Hirosaki Med. J. 61(Suppl.) : S1-S10, 2010

\title{
PRANDIAL INCREASES OF LEPTIN AND OREXIN IN THE BRAIN MODULATE SPATIAL LEARNING AND MEMORY
}

\author{
Yutaka Oomura $^{1)}$, Shuji Aou ${ }^{2)}$, Kouji Fukunaga ${ }^{3)}$, Sigeki Moriguchi ${ }^{3)}$ and Kazuo Sasaki ${ }^{4)}$
}

\begin{abstract}
Leptin is well known to be involved in the inhibition of feeding, thermogenesis, reproduction and neuroendocrine functions through its actions on the rodent hypothalamic receptors. Leptin facilitated the presynaptic transmitter release and postsynaptic sensitivity to the transmitters in the hippocampal CA1 neurons. Thus longterm potentiation (LTP) and the phosphorylation of $\mathrm{Ca}^{2+} /$ calmodulin protein kinase II (CaMK II) were facilitated in the CA1 neurons. Therefore behavioral performance related to spatial learning and memory was improved by leptin in vivo applications. Orexin-A produced by glucose-sensitive neurons in the lateral hypothalamic area (LHA) and released during food intake facilitates feeding. Orexin-A suppressed LTP and CaMK II phosphorylation without affecting the presynaptic transmitter release. Therefore behavioral performance on learning and memory was impaired. The present studies suggest that leptin and orexin signalings in the brain may have important implications for cognitive function.
\end{abstract}

Hirosaki Med. J. 61, Supplement : S1-S10, 2010

Key words: Leptin; Orexin; CaMK II phosphorylation; Facilitation and impairment of learning and memory in rodents

\section{Introduction}

Leptin, an adipocytokine encoded by an obesity gene and expressed in adipose tissue, is increased in rat plasma during eating, the rise being from approximately 2.3 to $3.8 \mathrm{ng} / \mathrm{ml}$ (i.e. to $2.4 \times 10^{-10} \mathrm{M}$ ). Approximately $1 / 5000$ of plasma leptin enters into the brain and binds to widely distributed long form leptin receptors (OBRb) in the neurons especially in the hypothalamus, modulates neuronal activity and affects feeding behavior, thermogenesis and neuroendocrine status. For example, leptin inhibits food intake through the inhibition of glucose-sensitive neurons in the LHA and medial part of arcuate nucleus, feeding center, and facilitates the glucoreceptor

Department of Integrative Physiology, Graduate School of Medical Sciences, Kyushu University ${ }^{11}$, Department of Brain Science and Engineering, Graduate School of Life Science and Systems Engineering, Kitakyushu Institute of Technology ${ }^{2}$, Department of Pharmacology, Faculty of Pharmacy, Tohoku University ${ }^{3)}$ and Division of Bio-Information Engineering, Faculty of Engineering, University of Toyama, Toyama ${ }^{4}$

${ }^{1)}$ Maedashi 3-1-1, Higashi-ku, Fukuoka, 812-0054, Japan. neurons in the ventromedial nucleus and lateral part of the arcuate nucleus, satiety center ${ }^{1)}$. Thus leptin is one of endogenous satiety substances. Leptin also activates the neuronal activity of the parvocellular neurons in the paraventricular nucleus and modulates the sympathetic nerve activity, thus the thermogenesis and neuroendocrine functions. OBRbs have been found to be expressed in the CA1 region of the hippocampus. These findings suggest that leptin may affect the synaptic plasticity and behavioral performance related to learning and memory. Indeed, it has been reported that the hippocampal synaptic plasticity is modulated by leptin in rats with intact leptin receptors ${ }^{2,3}$, whereas it is impaired in leptin receptor deficient rodents ${ }^{4-6)}$. In the present

Tel. 092642 6087, Fax. 092642 6093,

y_oomura25@hotmail.com

2) Hibikino 1-22-101, Wakamatu-ku, Kitakyushu, 8080135, Japan. Tel. 093695 6105, Fax. 093695 6105, aou@brain.kyutech.ac.jp

3) Aoba 6-3, Aoba-ku, Sendai, Japan. 980-8578, Japan. Tel. 022795 6836, Fax. 0227956835 , fukunaga@mail.pharm.tohoku,

4) Gofuku 3150, Toyama, Japan 930-8555. Tel. 076445 6719, Fax. 076445 6723, sasaki@eng.u-toyama.ac.jp 
report, first we mention the effects of leptin on behavioral performance in spatial learning and memory task, LTP at Schaffer collateral-CA1 synapses, presynaptic and postsynaptic actvities in hippocampal CA1 neurons and CaMK II activity in CA1 region that exhibits LTP, and show that the low physiological dose of leptin enhances behavioral performance and LTP, whereas the high dose of leptin, namely plasma concentration, impairs them ${ }^{3}$.

Orexin-A produced in the glucose-sensitive neurons in the lateral hypothalamic area and released into the brain during food intake. Orexin-A facilitates the glucose-sensitive neurons and suppresses the glucoreceptor neurons, thus orexin- $\mathrm{A}$ is one of endogenous hunger substances ${ }^{1,7}$. Orexin-A exhibits this function through orexin 1 receptor (OX1R) and orexin 2 receptor $(\mathrm{OX} 2 \mathrm{R})^{7,8)}$ and has the opposite effects of leptin, namely impairments of learning and memory performance and $\mathrm{LTP}^{9)}$.

\section{Results-1 Effects of leptin on learning and memory on rodents}

2. 1. Facilitation of learning and memory and synaptic plasticity

The effects of leptin on the Morris water maze performance were carried out. Short swimming times to find a hidden platform inside the pool indicate more rapid learning. Thirty min before the task on day one various concentrations of leptin was intra-venously injected. On day one there was no difference between the leptin and control vehicle groups. On days $2-4$, swimming time became shortened day by day in all groups including the vehicle control group. This showed the training effect. The only value significantly shorter than that for the control vehicle injected group was obtained on day 2 for the $50 \mu \mathrm{g} / \mathrm{kg}$ leptin iv group $(p<0.05)$ as shown in Fig.1 A. Swimming time was significantly longer for the $500 \mu \mathrm{g} / \mathrm{kg}$ group than the control group on day $2-4(p<0.01)$. In the probe test the swimming time in the goal area (up to $60 \mathrm{~s}$ ) was measured in the five groups ( $n=5$ in each group). As shown in Fig.1 B, the $50 \mu \mathrm{g} / \mathrm{kg}$ leptin group spent significantly more time swimming and the $500 \mu \mathrm{g}$ $/ \mathrm{kg}$ group spent significantly shorter time in the goal are on probe test days 1 to 3 than the control group. These results indicate that $50 \mathrm{~g} /$ $\mathrm{kg}$ leptin group consolidates memory process so that it can last at least for 2 days after the Morris water maze test ${ }^{3)}$.
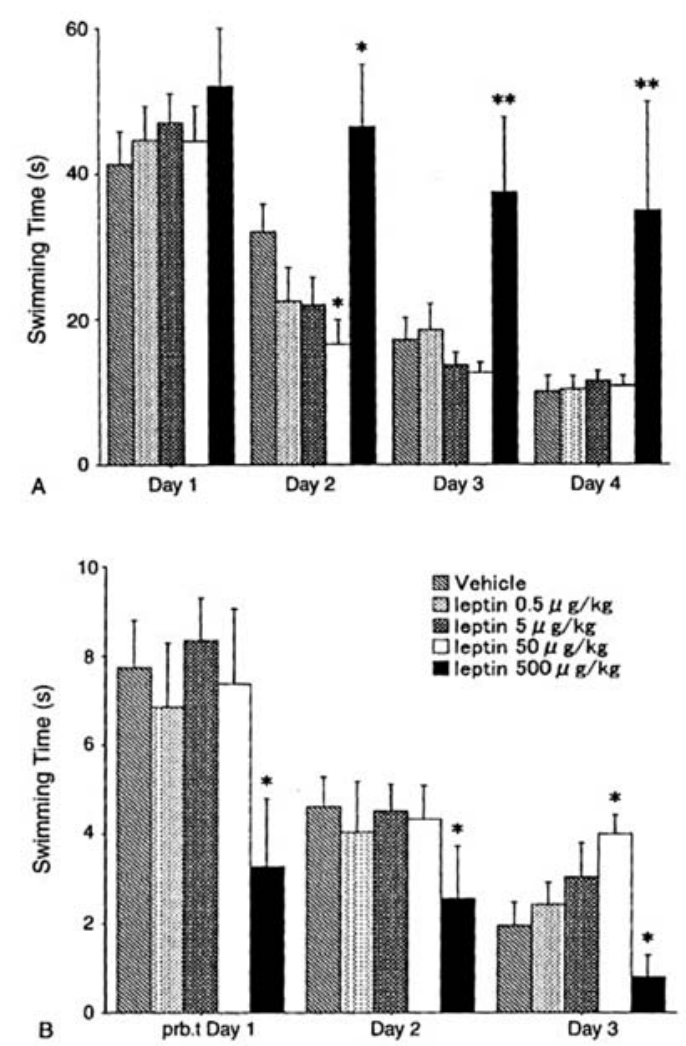

Figure 1 Enhancement of Morris water maze performance by the low concentration of leptin and impairment by the high concentration of leptin. Leptin $0.5 \mu \mathrm{g} / \mathrm{kg}$ group, $\mathrm{n}=16$, other group, $\mathrm{n}=20$. The shortest swimming time (A) occurred on day 2 in the $50 \mu \mathrm{g} /$ $\mathrm{kg}$ leptin group (compared to vehicle group). Swimming time for finding the platform was significantly greater at $500 \mu \mathrm{g} / \mathrm{kg}$ than in control on days 2 to 4 . (B) Probe test after withdrawing the platform. The $50 \mu \mathrm{g} / \mathrm{kg}$ leptin group spent a longer time in the goalarea than the vehicle group on probe test (prb. t) day $3(p<0.05)$, whereas the $500 \mu \mathrm{g} / \mathrm{kg}$ leptin group spent less time than the vehicle group on probe test days $1-3(\mathrm{p}<0.05) .{ }^{*} p<$ 0.05. (Adapted from Oomura et al., 2006) 
Fig. $2 \mathrm{~A}$ and $\mathrm{B}$ provide the effects of various concentrations of leptin on LTP on CA1 neurons in hippocampal slice preparations. The percentage of the increase in field (f) EPSP amplitude in the $10^{-12} \mathrm{M}$ leptin was approximately $250 \%$, whereas that in the normal Krebs-Ringer treated slices was approximately $150 \%$. At the $10^{-10} \mathrm{M}$ leptin LTP was suppressed ${ }^{3}$.

\section{2. Effects of leptin on the presynaptic and postsynaptic activities}

\section{2. 1. Presynaptic activity}

Measurement of spontaneous mEPSCs in CA1 neurons in hippocampal slice preparations can be used to obtain additional information on how leptin affects presynaptic transmitter release in the process by which LTP is induced. As shown in Fig. 3, though no change in the mESPCs
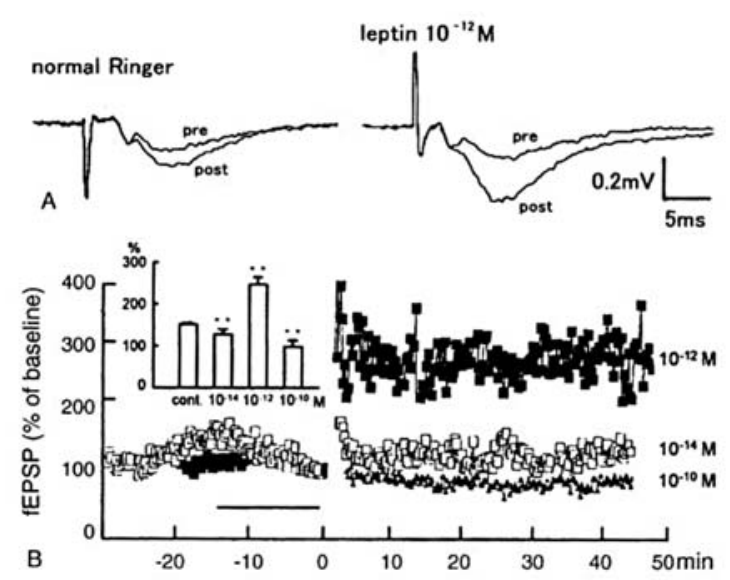

Figure 2 Leptin effects on LTP in CA1 neurons. (A) Example records of fEPSPs 20 min before (pre) and after (post) tetanization. Left, normal Krebs- Ringer, right, $10^{-12} \mathrm{M}$ leptin. Leptin applied for 15 min just before tetanic stimulation. (B) Percent change of fEPSP amplitudes. Tetanic stimulation took place at zero time (see abscissa). Solid horizontal lines, leptin application for $15 \mathrm{~min}$. Ordinate, amplitudes of fEPSPs as percentage of baseline (100\%). Inset, mean amplitudes of fEPSPs (as percentage of baseline) following leptin administration; measurements were made over a $10 \mathrm{~min}$ period. (30-40 min after tetanic stimulation) $10^{-14}, 10^{-12}, 10^{-10} \mathrm{M}$ leptin, $\mathrm{n}=3$; control, $\mathrm{n}=6$. Leptin groups are all significantly different from the controls. ${ }^{* *} p<$ 0.01. (Adapted from Oomura et al., 2006) frequency the amplitudes were increased by approximately $130 \%$ in $10^{-12} \mathrm{M}$ leptin, whereas no significant change was taken place in $10^{-10} \mathrm{M}$ leptin ${ }^{3)}$.

\section{2. 2. Postsynaptic activity}

Postsynaptic responses evoked in CA1 neurons by various transmitter candidates can be used to obtain additional information on how leptin might be affecting postsynaptic receptors in the process in leading to LTP induction. The intracellularly recorded postsynaptic responses of CA1 neurons in hippocampal slice preparations evoked by quiscualic acid (Quis, $10 \mathrm{mM}$ in 150 $\mathrm{mM} \mathrm{NaCl}$ ), $\gamma$-aminobutyric acid (GABA, $0.5 \mathrm{mM}$ in $150 \mathrm{mM}, \mathrm{NaCl}$ ), and N-methyl-aspartic acid (NMDA, $10 \mathrm{mM}$ in $150 \mathrm{mM} \mathrm{NaCl}$ ) ejections

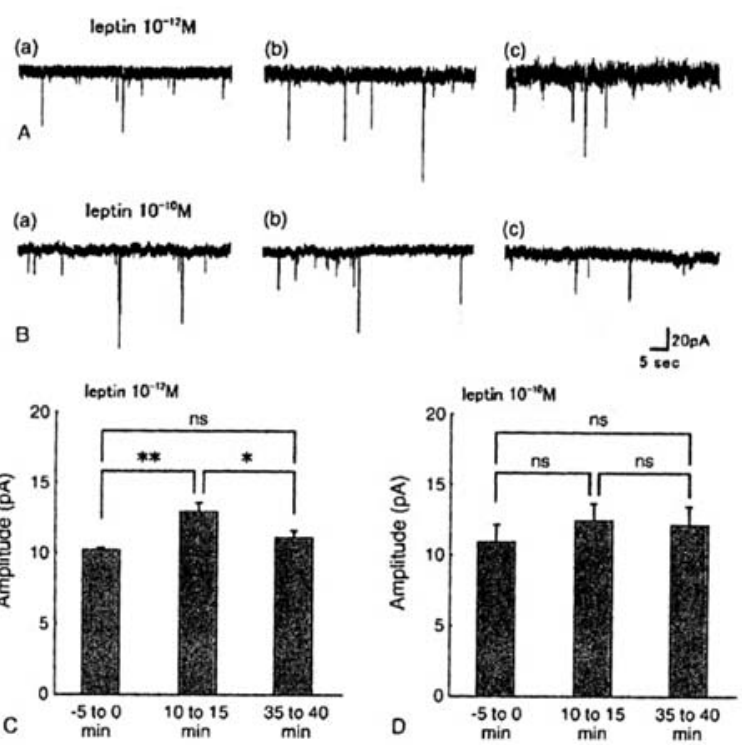

Figure 3 Effect of leptin on spontaneous mEPSCs in CA1 neurons. (A) and (B) Examples of high sweep records of mEPSC at 5 min (a) before, $10 \mathrm{~min}(\mathrm{~b})$ and $35 \mathrm{~min}$ (c) after $10^{-12} \mathrm{M}(\mathrm{n}$ $=3)$ and $10^{-10}$ M leptin $(\mathrm{n}=4)$ applications, respectively. Leptin application, $5 \mathrm{~min}$. Membrane potential, clamped at $-70 \mathrm{mV}$. (C) and (D) Effects of $10^{-12}$ and $10^{-10} \mathrm{M}$ leptin on mEPSC amplitudes, respectively. Left, middle and right histograms in (C) and (D) are mean amplitudes for 5 min periods just before, from $10 \mathrm{~min}$ to $15 \mathrm{~min}$ and from 35 to $40 \mathrm{~min}$ after leptin application, respectively. Significant increase in mEPSC amplitude following $10^{-12} \mathrm{M}$ leptin was seen. ${ }^{*} p<0.05,{ }^{* *} p<0.01$. (Adapted from Oomura et al., 2006) 
electrophoretically through the glass capillary multibarreled electrods placed on the apical dendrites of the same recording neurons were obtained in normal Krebs-Ringer solution. The measurements were repeated in the same neuron over the next 15 min with $10^{-12}$ or $10^{-10} \mathrm{M}$ leptin in the perfusate, and then repeated again in normal Krebs-Ringer solution. In four success neurons, as shown in Fig. 4A, the applications of $10^{-12} \mathrm{M}$ leptin concentration did not show any changes

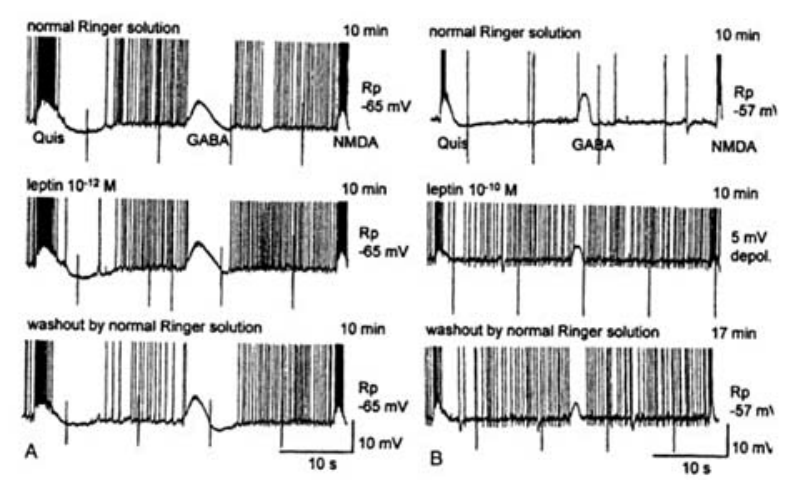

Figure 4 Effect of leptin on intracellularly recorded postsynaptic responses induced in a CA1 neuron by electrophoretic application (25 nA for 1 s) of Quis, GABA and NMDA. (A) and (B) Effect of $10^{-12}$ and $10^{-10} \mathrm{M}$ leptin application, respectively. Upper traces in (A) and (B), 10 min after recording had stabilized in normal Krebs- Ringer solution. Middle traces in (A) and (B) $10 \mathrm{~min}$ after $10^{-12}$ and $10^{-10} \mathrm{M}$ leptin application, respectively. No observable changes in postsynaptic responses were seen following $10^{-12} \mathrm{M}$ leptin application, whereas suppression of postsynaptic responses to all three transmitters was seen following $10^{-10} \mathrm{M}$ leptin application. Membrane potential (Rp: -65 $\mathrm{mV}$ ) was not changed by application of $10^{-12}$ $\mathrm{M}$ leptin, but a $5 \mathrm{mV}$ depolarization (depol) occurred following $10^{-10} \mathrm{M}$ leptin application. Lower traces in (A) and (B), 10 and $17 \mathrm{~min}$ after washout respectively. (Adapted from Oomura et al., 2006) in the postsynaptic responses to the Quis, NMDA and GABA. However in $10^{-10} \mathrm{M}$ leptin the postsynaptic responses to these transmitter candidates were all attenuated, as shown in Fig. $4 \mathrm{~B}$. At that time the membrane potential of the CA1 neurons were about $5 \mathrm{mV}$ depolarized ${ }^{3)}$.

\section{3. Effect of leptin on intracellular $\mathrm{Ca}^{2+}$ in single isolated CA1 neurons}

As mentioned above, the different effects caused by the different leptin concentrations could be related to the $\left[\mathrm{Ca}^{2+}\right] \mathrm{i}$ in the postsynaptic CA1 neurons. We measured the $\left[\mathrm{Ca}^{2+}\right]_{\mathrm{i}}$ concentration in single $\mathrm{CA} 1$ neurons at different leptin concentrations. The basal level of $\left[\mathrm{Ca}^{2+}\right] \mathrm{i}$ was 115 $\pm 44 \mathrm{nM}(\mathrm{n}=6)$. Application of leptin of $10^{-12}$ and $10^{-10} \mathrm{M}$ induced marked dose dependent increase in $\left[\mathrm{Ca}^{2+}\right] \mathrm{i}$ was $329 \pm 97 \mathrm{nM}(\mathrm{n}=6)$ and $739 \pm 250 \mathrm{nM}(\mathrm{n}=6)$ respectively $^{3}$.

\section{4. Effect of leptin on CaMK II activity}

The activation and autophosphorylation of CaMK II is one of the molecular signal transduction mechanisms known to LTP and to learning and memory performance ${ }^{10)}$. We measured the effect of leptin on the activity of CaMK II in the rat CA 1 regions of slices in which LTP had been induced as described above. Control slices were stimulated and potentiated, but not exposed to leptin. As shown in the Table, $10^{-12} \mathrm{M}$ leptin induced a significant increase in $\mathrm{Ca}^{2+}$-independent CaMK II activity $(p<0.05)$ without a significant increase in total CaMK II activity, but $10^{-10} \mathrm{M}$ leptin showed the significant

Table 1 Effect of leptin on CaMK II activity. (Adapted from Oomura et al., 2006)

\begin{tabular}{lccc} 
Table 1 - Effects of leptin on CaMK II activity & & \\
& $\begin{array}{c}\text { (A) } \mathrm{Ca}^{2+} \text {-independent activity } \\
\text { (nmol/mg/min) }\end{array}$ & $\begin{array}{c}\text { (B) Total activity } \\
\text { (nmol/mg/min) }\end{array}$ & $\begin{array}{c}\text { "Ca }{ }^{2+} \text {-independence" } \\
\text { (A/B } \times 100 \%)\end{array}$ \\
\hline Control $(n=8)$ & $25.3 \pm 6.87$ & $232.5 \pm 15.46$ & $15.3 \pm 3.38$ \\
$10^{-12} \mathrm{M}$ leptin $(n=10)$ & $42.3 \pm 5.15^{\circ}$ & $239.1 \pm 18.65$ & $18.0 \pm 3.25$ \\
$10^{-10} \mathrm{M}$ leptin $(n=8)$ & $31.3 \pm 3.74^{*}$ & $221.6 \pm 21.02$ & $14.2 \pm 2.55^{*}$
\end{tabular}

$p<0.05$ in comparison with control.

- $p<0.05$ in comparison with $10^{-12} \mathrm{M}$ leptin. 
lowering of $\mathrm{Ca}^{2+}$-independent CaMK II activity. These results indicate that a specific dosedependent increase in CaMK II activity at $10^{-12}$ $\mathrm{M}$ leptin is associated with the induction of LTP facilitation $^{3)}$.

\section{Results-2 Impairement effects of orexin on long-term potentiation and spatial learning and memory in rodents}

\section{1. Introduction}

Hypothalamic peptide, orexin-A produced in the glucose-sensitive neurons in the LHA and dorsomedial hypothalamic nucleus stimulates food intake ${ }^{1,7)}$. Orexin-A containing terminals were found in the hippocampus, amygdala, central gray, locus coeruleus, dorsal raphe, dorsal motor nucleus of the vagus, perirhinal sensory and motor cortex, and the cerebellum ${ }^{7.8}$. Two types of orexin receptors, OX1R and OX2R distribute widely in the CNS: high levels of OX1R mRNA are found in the hippocampal formation, and OX2R mRNA is found in the cerebral cortex. Consequently, the activation of functional orexin circuits can influence mainly learning and memory and arousal ${ }^{8,9)}$. The purpose of the present study was to determine the effects of different doses of orexin-A on 1) performance in the Morris water maze test and 2) on LTP and paired-pulse facilitation in the Schaffer collateral synapses.

\section{2. Orexin-A impairs learning and memory in the water maze in rodents}

The doses of orexin-A were selected based on their influences on the food intake ${ }^{1,7,8)}$. Control, $5 \mu \mathrm{ACSF}(\mathrm{n}=10), 1$ and $10 \mathrm{nmol}$ orexin-A in $5 \mu \mathrm{l}(\mathrm{n}=6,8$ respectively $)$ were i.c.v. injected. In Fig.5A, the mean swimming time shows significant differences between the two orexin-A groups, namely orexin-A group was performing less efficiency than the control, particularly on block 2 and 3 . The results of the probe test in Fig.5 B was more pronounced regarding the different doses of orexin. In the goal area, there was a significant dose related impaired retention, in term of where the platform had been located ${ }^{9}$.

\section{3. Orexin-A depresses LTP in Schaffer collateral -CA1 synapses in hippocampal slices}

As shown in Fig.6 A and B, after the tetenic stimulation, $10 \mathrm{nM}$ orexin-A reduced the potentiation of fEPSPs amplitudes. Thus LTP was suppressed. There was no effect of orexi-A, even $30 \mathrm{nM}$ concentration, applied after the tetanus (C). The effects of $10 \mathrm{nM}$ orexin-A was the approximately the same as those of $30 \mathrm{nM}$ orexin.

In normal Krebs-Ringer solution with a low frequency stimulation, fEPSP mainly results from
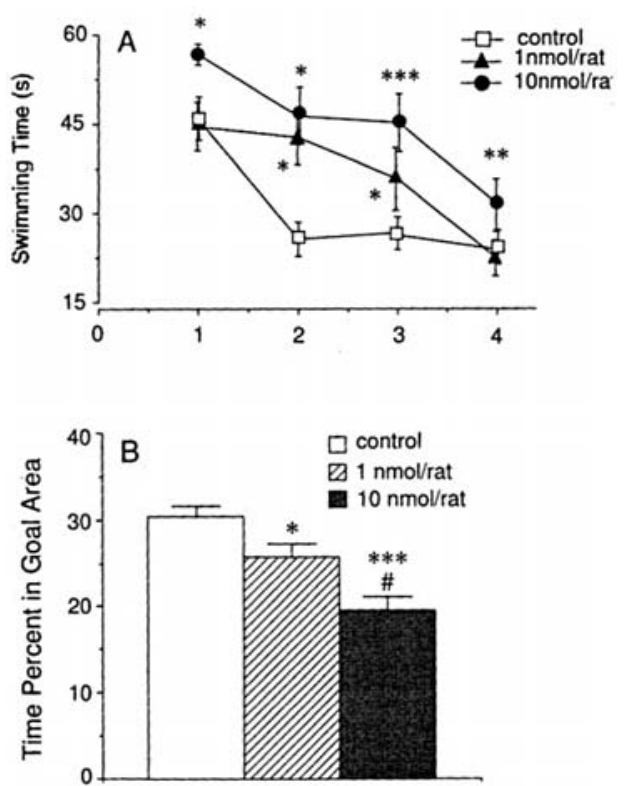

Figure 5 Effect of i.c.v. injection of orexin-A (1, $10 \mathrm{nmol})$ on water maze performance in an invisible platform condition. (A) Escape latency. Impairment in swimming time occurred on blocks 2 and 3 in the 1 nmol group and on blocks 1,2 , and 3 in the 10 nmol group. Swimming time was significantly longer at 1 and $10 \mathrm{nmol}$ than the control. ${ }^{*} P<0.05,{ }^{* *} P<0.01$, ${ }^{* * *} P<0.001$ (vs. control). (B) Probe test on day 2 after trials with the platform (block 4), a free-swim that without the platform. Goal area one quadrant of the pool where the platform was formerly located, $70 \mathrm{~cm}$ in diameter. The swimming time \% in the goal area. Significantly shorter times are seen in the 1 and $10 \mathrm{nmol}$ groups than in the control group. (Adapted from Aou et al., 2003) 
2-amino-3-hydroxy-5-methyl-isoxozole (AMPA) response. After a tetanic stimulation, N-methyl$\mathrm{D}$-aspartate (NMDA) response is activated and lead to LTP. Because orexin-A had no effect on the base line fEPSP in the normal KrebsRinger solution, orexin-A had no effect on AMPA response. In order to record the NMDA component of EPSP, we used $10 \mu \mathrm{M} 6$-cyano7-nitroquinoxaline-2,3-dione (CNQX) to block the AMPA response and changed to a solution with low $0.1 \mathrm{mM} \mathrm{Mg}^{2+}$ and $50 \mu \mathrm{M}$ picrotoxin
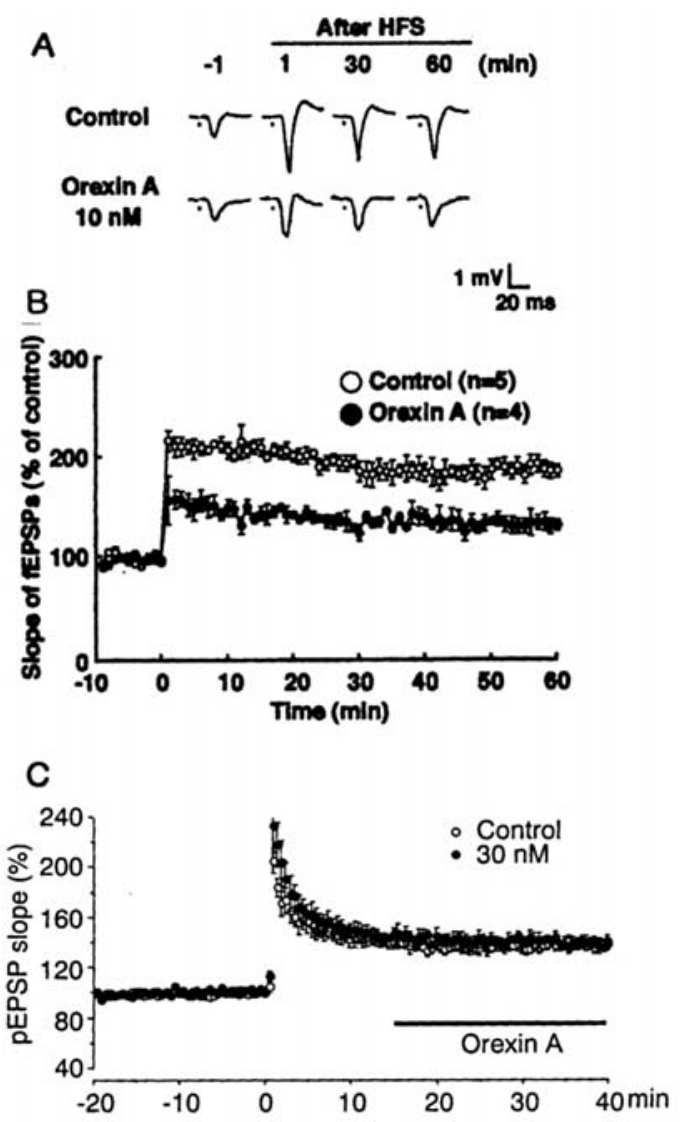

Figure 6 Effects of bath application of orexin-A on LTP. The mean \pm S.E.M. percent changes of slopes of fEPSP before and following a tetanic stimulation (time 0 on abscissa). Orexin-A was applied for 15 min just before tetanic stimulation. (A), fEPSPs amplitudes before and after tetanic stimulation. Uper, before orexin-A application, lower, after $10 \mathrm{nM}$ orexin-A application. (B) LTP. $10 \mathrm{nM}$ orexin-A was applied for 15 min just before tetanic stimulation. Orexin-A suppressed LTP. (C) No effect of orexin-A on the maintenance of LTP when orexin-A was applied after tetanus. (Adapted from Aou et al., 2003) to enhance the NMDA response. Under this condition, the amplitudes of fEPSPs decreased only after the application of orexin-A. This finding indicated that orexin-A only affected NMDA receptors.

\section{4. Effect of orexin-A on paired pulse facilitation}

This experiment was carried out to determine the possible effects of 10 and $30 \mathrm{nM}$ orexin- $\mathrm{A}$ on presynaptic release of transmitter. The results are summarized in Fig. 7 where the percent change in the first pulse $\mathrm{p} 1$ and the retio $\mathrm{p} 2 /$ pl for each min is presented before and after the administration of the two doses of orexin- $A$
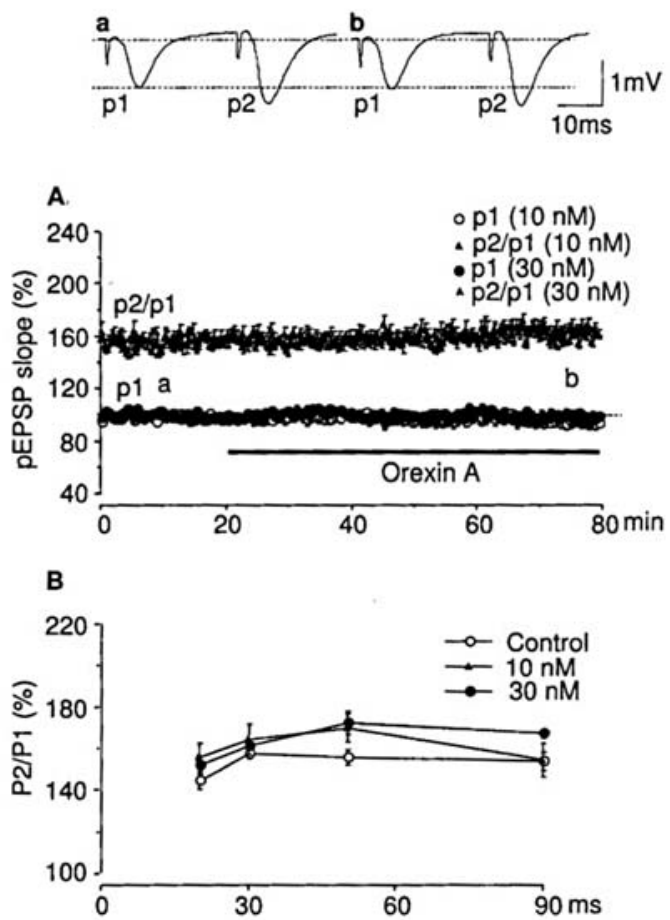

Figure 7 The presynaptic effects of orexin-A were investigated by mean of paired pulse stimulation. Upper recordings, first and second fEPSP at $30 \mathrm{~ms}$ stimulus interval. a and b, selected where indicated in lower part by corresponding letters. (A) amplitudes of first fEPSP and amplitude ratio $\mathrm{p} 2 / \mathrm{p} 1$, interval $30 \mathrm{~ms}$. Orexin-A had no effect on the pl amplitude and ratio. Solid horizontal lines, orexin-A $(10,30 \mathrm{nM})$ application. (B) the amplitude ratio $\mathrm{p} 2 / \mathrm{p} 1$ following orexin-A application as a function of the paired-pulse stimulus interval. No significant difference in the ratio occurred. Test stimuli, every $30 \mathrm{~s}$ ( $\mathrm{n}=5-7$, for each group) (Adapted from Aou et al., 2003) 
for $60 \min (\mathrm{n}=5$, each). Because there was no significant change in the fEPSP amplitudes and the $\mathrm{p} 2 / \mathrm{p} 1$ ratios with an interpulse interval of $30 \mathrm{~ms}$, another experiment was carried out utilizing intervals of $20,50,90 \mathrm{~ms}$ at the same dosed of orexin- $\mathrm{A}, 10$ and $30 \mathrm{nM}(\mathrm{n}=5$, each, in comparison with the control $(n=7)$. The results, as shown in Fig.7 B, were similar to those of the previous experiment. the mean \pm S.E.D. of $\mathrm{p} 2 /$ pl ratio in percent for control, 10 and $30 \mathrm{nM}$ orexin-A applications were not significant between the different intervals. As a result, there was no evidence of any orexin-A effect on the presynaptic transmitter release.

\section{5. Effect of orexin-A on CaMK II acitity}

As mentioned on the leptin effects on the facilitations of learning and memory and LTP, the two factors have the intimately close relationship. Orexin-A has the impairments in both learnig and memory and LTP, thus we measured the CaMK II activation on hippocampal CA1 neurons under the orexin-A applications. Orexin-A at $10 \mathrm{nM}$ and $30 \mathrm{nM}$ concentrations suppressed the $\mathrm{Ca}^{2+}$-indepenent CaMK II activity. The activity levels were $25.5 \pm 5.37$ in the control, $20.2 \pm 4.37$ in $10 \mathrm{nM}$ orexin- $\mathrm{A}$ and $18.6 \pm 5.68 \mathrm{nmol} / \mathrm{mg} / \mathrm{min}$ in $30 \mathrm{nM}$ orexin-A $(\mathrm{p}<0.05$, at control to $10 \mathrm{nM}$ orexin).

\section{Physiological significance of leptin and orexin- $A$}

The present results clearly indicate that the physiological concentration of leptin in the brain, $10^{-12} \mathrm{M}$ facilitates LTP and phosphorylation of CaMK II, and enhances spatial learning and memory, but the plasma concentration of leptin $10^{-10} \mathrm{M}$ impaired these. The close association between enhanced hippocampal LTP and facilitated learning and memory has been reported ${ }^{3)}$. When we assume that a 200-250 $\mathrm{g}$ rat has a plasma volume of approximately $10 \mathrm{ml}, 50 \mu \mathrm{g} / \mathrm{kg}$ leptin intravenously applied would be equivalent in plasma to about $10^{-8} \mathrm{M}$ and $500 \mu \mathrm{g} / \mathrm{kg}$ dose to $10^{-7} \mathrm{M}$. As mentioned in the introduction, less than $1 / 5000$ of ${ }^{125}$ I-leptin administered intravenously enters into the brain ${ }^{3,11)}$, since 50 $\mu \mathrm{g} / \mathrm{kg}$ leptin is the physiological concentration in the brain, whereas $500 \mu \mathrm{g} / \mathrm{kg}$ leptin is the pharmacological concentration ${ }^{3}$.

It is known that a modulate increase of $\left[\mathrm{Ca}^{2+}\right] \mathrm{i}$, say $329 \pm 97 \mathrm{nM}$ in CA 1 neurons activates the $\mathrm{Ca}^{2+}$-independent activity of CaMK II, whereas a large and prolonged increase of $\left[\mathrm{Ca}^{2+}\right] \mathrm{i}$, say more than $600 \mathrm{nM}$ at the $10^{-10} \mathrm{nM}$ leptin concentration inhibits it, possibly through the activation of calcineurin $^{6,12,13)}$.

Calcineurin is a protein phosphatase that brings the CaMK II dephosphorylation. Thus high $\left[\mathrm{Ca}^{2+}\right] \mathrm{i}$ at $10^{-10} \mathrm{M}$ leptin, instead of activation of CaMK II may activate the calcineurin.

The present experiments also demonstrated that orexin-A inhibited the performance of rats in the invisible platform condition in the Morris water maze test, suggesting that orexin-A impaired the spatial performance but did not induce the abnormality in swimming ability, thigmotaxis, and vision in vivo condition. The present results also indicate that orexin-A inhibits the LTP in the hippocampus under in vitro conditions.

The paired pulse facilitation experiment indicated that the orexin-A induced inhibition of LTP is not mediated by the decrease in amount of transmitter released from presynaptic terminals but solely by the postsynaptic NMDA receptors while the AMPA receptors are not involved. The LTD, did not mentioned in the present results, but actually did not change, thus indicating no involvement of the calcineurininhibitor-1 phosphatase cascade ${ }^{14}$.

The concentration of orexin-A in the rat $\mathrm{CSF}$ is not yet known. We gave $1-10 \mathrm{nmol} / \mathrm{rat}$ orexin-A and the concentration can be estimated as 3.3 to $33 \mu \mathrm{M}$ when the volume of CSF is approximately $300 \mu 15)$. Since the diffusion 
between the ventricle and the hippocampus dose not exceed $2 \%^{16)}$, the concentration of 3.3 to 33 $\mu \mathrm{M}$ orexin in CSF becomes $6.6 \times 10^{-8} \mathrm{M}$ to $6.6 \mathrm{X}$ $10^{-7} \mathrm{M}$ in the hippocampus. If we assume that the production of CSF is $0.5 \%$ of the total volume per min then the concentration of orexin-A would be diluted to $40 \%$ of the initial concentration. As a results, the concentration in the hippocampus becomes $2.6 \times 10^{-8} \mathrm{M}$ to $2.6 \times 10^{-7} \mathrm{M}$.

\section{Conclusion}

Figure 8 shows the conclusive variegated physiological significance of leptin. During food intake, leptin released into plasma from the adipocytes reaches into the brain. The concentration of leptin in the brain is approximately $1 / 5000$ of its plama concentration. Leptin diffuses into the brain parenchyma and first reaches the hypothalamus and suppresses food intake through the inhibition of the activity of the glucose-sensitive neurons in the LHA and the medial arcuate nucleus, feeding related areas and through the activation of the glucoreceptor neurons in the ventromedial nucleus and the lateral part of arcuate nucleus, satiety related areas. Secondly, leptin reaches the hippocampus and facilitates synaptic plasticity and improves spatial learning and memory performance through the facilitations of LTP and CaMKII phosphorylation in the CA1 neurons. Thirdly, leptin reaches to the neurons in the parvocellular part of the paraventricular nucleus and facilitates the release of the corticosterone releasing hormone $(\mathrm{CRH})$ and also activates not only hypothalamic-pituitary-adrenal axis but also efferent sympathetic outflow.

Corticosterone released from the adrenal gland can also modulate LTP and promote the learning and cognitive processes ${ }^{17}$. In fact, the clinical data suggest that $\mathrm{CRH}$ deficiencies

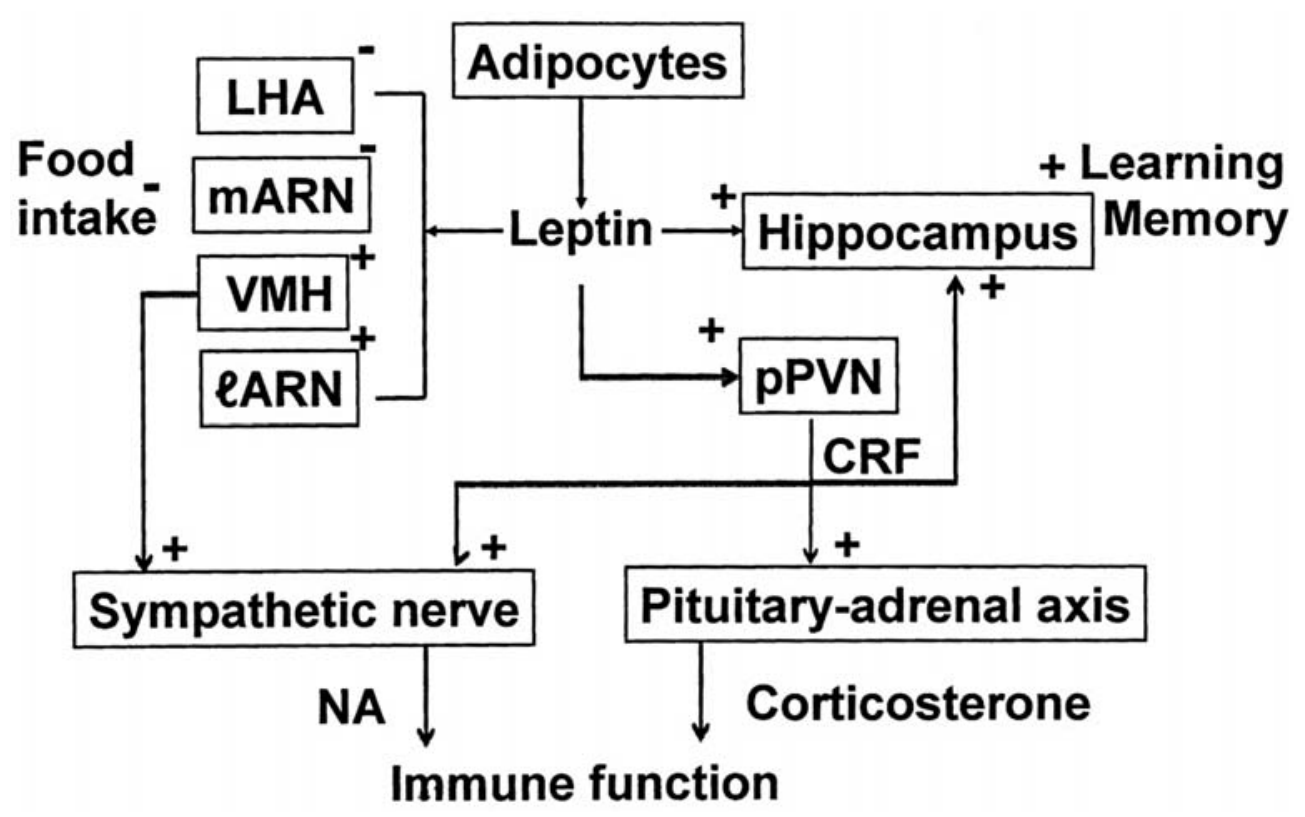

Figure 8 Deduced physiological action of endogenous satiety substance, leptin. Leptin released into plasma during food intake from the adipocytes enters into the brain only by $1 / 5000$ of the plasma concentration. Leptin reaches the glucose-sensitive neurons in the LHA and the medial part of the arcuate nucleus (feeding related centers) and the glucoreceptor neurons in the ventromedial nucleus and lateral part of the arcuate nucleus (satiety related centers) and inhibits feeding. Then leptin reaches the hippocampus and facilitates spatial learning and memory. Leptin reaches the neurons in the parvocellular part of the paraventricular nucleus (pPVN) and activates these neurons causing $\mathrm{CRH}$ release. These neurons and $\mathrm{CRH}$ activate efferent sympathetic outflow and pituitary-adrenal axis. Splenic sympathetic activation and released corticosterone modulate immune function. 
can be detected in the brain in patients with neurodegenerative dementia. The parallel activation of the sympathetic outflow to the adrenal gland and brown adipose tissue may show that leptin has a multifunctional roles in the control of neuronal and/or endocrinological activities. The iv administration of leptin induces hyperthermia corresponding to the postprandial hyperthermia, in awake and freely moving rats. Corticosterone and splenic sympathetic activation attenuate the immune system. Since noradrenalin released into the spleen, attenuates the natural killer activity and corticosterone reduces the antibody-antigen reaction. In other words, the autoimmune reaction is reduced. That is a benefit to the living machinery.

The endogenous satiety substance, leptin plays physiological role in the presence of alimentation. This evidence indicates that food intake maintains not only the body energy homeostasis but also primes the brain for important functions.

Zucker fatty rats and $\mathrm{db} / \mathrm{db}$ mice who have the abnormal leptin receptors, therefore showed impairments of LTP and spatial learning and memory performance. These strains also showed lower basal levels of CaMK II activity in the CA1 region than the respective controls, and the levels did not respond to a brief tetanic stimulation".

Compared with one of the endogenous satiety substances leptin released from the adipocytes during feeding, orexin-A is one of the endogenous hunger substances released from the glucose-sensitive neurons in the LHA and other hypothalamic feeding related centers and promotes feeding. The activation of the LHA glucose-sensitive neurons also promotes the autonomic nervous system function, especially the sympathetic outflow. Thus orexin-A has an important role for keeping the healthy living body machinery. In spite of carrying such an important role, orexin-A has the other site of function, namely plastic impairment. During food intake we should concentrate this feeding behavior.

The present studies, anyway indicate the importance of leptin and orexin-A signaling for cognitive function.

\section{References}

1) Shiraishi T, Oomrura Y, Sasaki K, Wayner MJ. Effects of leptin and orexin-A on food intake and feeding related hypothalamic neurons. Physiol Behav 2000;71:251-61.

2) Shanley IJ, Irving AJ, Harvey J. Leptin enhances NMDA receptor function and modulates hippocampal synaptic plasticity. J Neurosci 2001;21:1-16, RC. 186.

3) Oomura Y, Hori N, Shiraishi T, Fukunaga K, Ishibashi M, Takeda H, Tuji M, Matsumiya T, Aou S, Li XL, Kono D, Uramura K, Sougawa H, Yada T, Wayner MJ, Sasaki K. Leptin facilitates learning and memory performance and enhances hippocampal CA1 long-term potentiation and CaMK II phosphorylation in rats. Peptides 2006;27:2738-49.

4) Hwa JJ, Chibaudi L, Compton D, Pawl AB, Strader CD. Intracerebroventricular injection of leptin increases thermogenesis and mobilizes fat metabolism in ob /ob mice. Horm Metab Res 1996;28:639-63.

5) Nagamori K, Ishibashi M, Shiraishi T, Oomura Y, Sasaki K. Effects of leptin on hypothalamic arcuate neurons in Wistar and Zucker rats: an in vitro study. Exp Biol Med 2003;228:1162-7.

6) Li XL, Aou S, Oomura Y, Hori N, Fukunaga K, Hori T. Impairment of long-term potentiation and spatial memory in leptin receptor-deficient rodents. Neuroscience 2002;113:607-15.

7) Sakurai T, Amemiya A, Ishii M, Matsuzaki I, Chemelli RM, Tanaka H, Williams SC, Richardson JA, Kozlowski GP, Wilson S, Arch JR, Buckingham RE, Haynes AC, Carr SA, Annan RS, McNulty DE, Liu WS, Terrett JA, Eishourbagy NA, Bergsma DJ, Yanagisawa M. Orexin and orexin receptors: a family of hypothalamic neuropeptides and $G$ protein-coupled receptors that regulate feeding behavior. Cell 1998;92:573-85. 
8) Date Y, Ueta Y, Yamashita H, Matsukura S, Kanagawa K, Sakurai T, Yanagisawa M, Nakazato M. Orexin, orexigenic hypothalamic peptides, interact with autonomic, neuroendocrine and neuroregulatory systems. Proc Natl Acad Sci USA 1999:96:748-53.

9) Aou S, Li X-L, Li A-J, Oomura Y, Shiraishi T, Sasaki K, Imamura T, Wayner MJ. Orexin-A (hypocretin-1) impaires Morris water maze performance and CA1-Schaffer collateral long-term potentiation in rats. Neuroscience 2003;119:1221-8.

10) Fukunaga K, Stopini I, Miyamoto E, Muller D. Long-term potentiation is associated with an increased activity of $\mathrm{Ca}^{2+} /$ calmodulin protein kinase II. J Biol Chem 1993;268:783-7.

11) M. von Heek. D. E. Mullins, M. A. Wirth, M. F. Gradino, A. B. Fawzi, D. S. Compton, C. F.france, L. M. Hoos, R. L. Casale, E. J. Sybertz, C. D. Strader, H. R. Devis. The relatioship of tissue localization, distribution and turnover to feeding after intraperitoneal ${ }^{125} \mathrm{I}$-leptin administration to $\mathrm{ob} / \mathrm{ob}$ and db/db mice. Horm Metab Res 1996;28:65-8.

12) Lisman J. The CaM kinase II hypothesis for the storage of synaptic memory. Trends Neurosci
1994:17:406-12.

13) Morioka M, Fukunaga K, Nagahiro S, Kurino M, Ushio Y, Myyamoto E. Glutamate- induced loss of $\mathrm{Ca}^{2+} /$ calmodulin depenent protein kinase II activity in cultured rat hippocampal neurons. J Neurochem 1995;84:2132-9.

14) Marenka RC. Synaptic plasticity in the hippocampus: LTP and LTD. Cell 1994;78:535-8.

15) Bass NH, Lundborg P. Postnatal development of bulk flow in the cerebrospinal fluid system of the albino rat : clearance of carboxyl $\left(\mathrm{C}^{14}\right)$ inulin after intrathecal infusion. Brain Res 1973;52:323-32.

16) Myers RD, Tytell M, Kawa A, Rudy T. Microinjection of ${ }^{3} \mathrm{H}$-acethylcholin, ${ }^{14} \mathrm{C}$ - serotonin and ${ }^{3} \mathrm{H}$-norepinephrine into the hypothalamus of rat : diffusion into tissue and ventricles. Physiol Behav 1971;7:743-51.

17) Behan DP, Heinrichs SC, Troncoso JC, Liu XJ, Kawas CH, Ling N, De Souza EB. Displacement of corticotrophin releasing factor from its binding protein as a possible treatment for Alzheimer's didease. Nature 1995;378:264-87. 